\title{
Editorial
}

\section{Ignác Fülöp Semmelweis, pioneer of clinical pathophysiology}

\author{
Doctor of Medical Sciences and Surgery, Master of Obstetrics \\ at the Pest Royal Hungarian University of Sciences, Professor of Practical Obstetrics
}

United Nations Educational, Scientific and Cultural Organization (UNESCO) has included the 150th anniversary of Ignaz Semmelweis' death in the list of notable anniversaries celebrated in 2015. The printed materials on the discovery of the causes of childbed fever and the introduction of accepted prevention was inscribed in UNESCO's Memory of the World Register in 2013. The achievements of the "saviour of mothers", the outstanding clinician and researcher earned him a fame that Semmelweis University and the whole world are righteously proud of.

Semmelweis (Fig. 1) was a unique personality, he did not like debates, he did not like writing, but he devotedly took care of every mother in labour with love and conscientiousness, fought for their lives regardless of their origin or social status, according to their need. Driven by the fear of the puerperal fever, he fought - with scientific thoroughness, detail and the perseverance of an obsessed and sober scientist - for a quick solution of the medical complication of unknown cause devastating mothers - sparing neither himself nor the prejudices, ranks or traditions of the time. He examined all the known ideas which could explain the cause of the disease regardless of their scientific value, and logically analysed and tested each one experimentally; and as a result refuted each in detail. He kept accurate records of the mothers' and patients' data and studied the changes in the statistics to find out the reasons, causes and correlations hidden behind the numbers. In his great compendium (Puerperal fever, aetiology, concepts and prevention, Fig. 2), he clearly states, right in the introduction, the pressing, almost unbearably burden of the conscientious obstetricians:

"... The cases, in which the obstetrician could intervene effectively, are incomparably negligible compared to the number of victims, that is, compared to the cases, when the intervention was unsuccessful. This dark side of obstetrics is puerperal fever ... I considered not just the therapy to be insufficient, but also the knowledge incomplete, because I have not found any explanation for its true cause in the presently valid aetiology of puerperal fever." (Ref. 1, p. 9)

What were the characteristic aetiological explanations of his era? Many considered puerperal fever an epidemic, others thought that inevitable atmospheric-cosmic-telluric influences affected women giving birth. They also believed that over crowdedness and the high number of births infected the ward. There were some who gave explanation for the puerperal fever with the exaggerated fear of women, or with the frightening noise of the bell used by Catholic priests in the ward when administering the Last Sacrament. "Some people believed that the reason of high mortality rate was the unmarried girls living in miserable conditions and doing hard work for their living during their pregnancies and living in 
misery, need and under depressive mental state, who may have even used abortive agents, etc." (Ref. 1, p. 35) While others supposed that the rougher examination methods of external students, having arrived from other universities for further education, resulted in fatal injuries.

To the good fortune of mothers, blind chance at the Obstetrics Department at Vienna University produced a specific clinical trial or "experimental" condition by providing two departments of clinic I and clinic II for mothers. Admissions were performed on a regular basis changing usually at 24 hour intervals. Maternal mortality at the clinic I was $6.56 \%$ on average, and $5.58 \%$ at the clinic II. In 1840 , it was decided to restructure the internal organisation of education and following this medical students were trained at clinic I, while the education of midwives was carried out at the clinic II. This administrative step almost immediately changed the mortality; at the site of medical student education mortality rate increased to $9.92 \%$, whereas at the site of midwifery training it decreased to $3.38 \%$. This striking change gave rise to great excitement among the patients, the doctors and professional leaders, but it was inexplicable according to the thinking of the time.

This was the period in Vienna when the famous, Moravian-born anatomist Rokitansky practiced and promoted Morgany's view - contrary to the earlier empirical patient care - that by a post-mortem approach, it is possible to find a treatment for the cause only after the anatomical and morphological changes have been determined. The tragicomic feature of this important provident principle is: first the patient has to die, and it is only after that one can make an accurate diagnosis and cure the disease effectively. Due to a spreading of this approach, the number of autopsies increased dramatically to an unbelievable extent in all medical areas.

Semmelweis himself dissected a lot, and the more mothers died, the more he wanted to see the morphology and determine the cause. This was completed by a diligent and consistent compilation, processing, comparison and tentative interpretation of the statistics. In addition to the anatomy, he deeply believed in figures as scientific research, even if he knew well, and drew attention to the fact that numbers may often be misleading. He knew, for example, that the head of the clinic I - just to avoid disclosing shameful mortality data, due to vanity and financial considerations - at the beginning of the appearance of puerperal fever, while the patients could be transported, often transferred them to other departments "to worsen statistic figures there". The committee legalizing and helping his decision tried to defend this procedure by stating that ill mothers are moved to departments where they are protected from the special effects causing the disease. This, however, did not help to save the mothers' lives.

The knowing bias of statistics, however, did not serve the good reputation of the clinic, it could not be denied that one in ten healthy young mothers at the department died together with their children. Staying at the clinic was much worse for the mothers than staying at home. Mothers dreaded the clinic with the bad reputation and they tried everything and invented various "tricks" to have the chance to be admitted to the other clinic.

It is hard even to imagine what the doctors might have felt in these circumstances. The incredibly large numbers of obviously unscientific explanations - which are absurd by modern standards and must even have been considered false even at their own time - were born to relieve this depressive burden.

Semmelweis considered and thought over each idea. The priests were asked not to ring their bells when called to the terminally ill. He paid attention to everything, followed the statistics and watched to determine if there was any change in the mortality rate, regardless of whether he considered the explanation to be credible or incredible. Each month, by analysing and comparing the data accumulated over the years he established that "along with 
a slow decrease in congestion in the ward an appropriate reduction in the mortality rate could not be experienced" (Ref. 1, p. 22), "in other words, the congestion did not play a role." (Ref. 1, p. 31) By hard work he demonstrated that neither the seasons, climatic conditions, fear, nor poverty were responsible for the differences in statistics. After all, the climatic conditions did not differ between the two departments, omitting ringing the bell did not help and mortality rate was not greater among the poor mothers having already given birth and who were admitted from the streets. He observed that in the cases of premature babies, where vaginal examination by the physician did not take place because of rapid delivery, the number of cases of puerperal fever was significantly less.

In the autumn of 1846 he came to the decision of announcing that puerperal fever was not an epidemia, i.e. general epidemic, but endemia that is a local problem. The causative factor could be found and was to be looked for directly in the immediate vicinity of the patients. He worked ever more, resected, calculated and searched but mortality rate was just increasing and in August 1846 it was over 18\% in the ward.

To demonstrate how difficult it is to see clearly in life, in spite of all efforts, and the complex reality, let me include a short description from Semmelweis' pen as testimony of those: "Even though I was convinced that the higher mortality in the Obstetrics Clinic I, is due to some indigenous, still unknown reason I unsuccessfully had been trying to discover so far, I was disturbed by the fact that newborns also contracted puerperal fever should they be either boys or girls. And since in addition I observed phenomena that I was not able to explain - e.g. that almost inevitably death occurred during long-term expansion of time, or when death did not follow the premature street births, or that the mortality at the First Department of Obstetrics - in contrast to my convictions - can be traced back to epidemic causes, or the fact of serial puerperal fever infections at the First Department of Obstetrics, finally the more favourable health conditions of the Second Department of Obstetrics (as compared to the First Department) made me think that the employees of the Second Department are either more clever and more careful in performing their duties than we were. The disrespect of the personnel against the employees of the First Department of Obstetrics resulted in such an unhappy mental state that it truly embittered my life. Everything was in question, everything seemed unclear, everything was doubtful, only the number of deceased remained undoubtedly steady." (Ref. 1, p. 46)

In spring 1847, Semmelweis received sad news. His revered and highly esteemed Kolletschka, professor of forensic medicine - after one of his students pricked him with his knife during autopsy - became ill with phlebitis and lymphangitis as well as bilateral pleuritis, pericarditis, peritonitis, cortico-cerebral inflammation and died.

In his book, he recalls the important event as follows: “... Due to my excitation over Kolletschka's death, the recognition rushed into my mind with uncontrollable force: Kolletschka deceased of the same condition as the several hundred with puerperal fever I saw to die. The mothers also died of phlebitis, lymphangitis, peritonitis, pleuritis and pericarditis and cortico-cerebral inflammation." (Ref. 1., p. 47) Microorganisms, bacteria were not unknown at that time, but at the Vienna University they were not paid their due attention. Semmelweis believed that "parts of corpse" entered the wound and the wound infected by corpse poison caused the death. "To destroy the substance of the corpse stuck to the hand-around the middle of 1847, I do not remember the day exactly - I used chlorina liquida, this was the liquid my students and I had to wash hands with before the examinations." (Ref. 1., p. 48) In the second half of May, they replaced it with the cheaper chloride of lime. For the next seven months, the mortality rate of the First Department of Obstetrics changed - according to Semmelweis - as shown in "TABLE XV". 


\begin{tabular}{|l|c|c|c|}
\hline \multicolumn{1}{|c|}{ In 1847 } & Number of births & Number of deceased & Percentage \\
\hline June & 268 & 6 & 2.38 \\
\hline July & 250 & 3 & 1.20 \\
\hline August & 264 & 5 & 1.89 \\
\hline September & 262 & 12 & 5.23 \\
\hline October & 278 & 11 & 3.95 \\
\hline November & 246 & 11 & 4.47 \\
\hline December & 273 & 8 & 2.93 \\
\hline
\end{tabular}

It is clear that the average mortality rate of seven months was 3.04\%. These figures were even further improved. "In 1848, when we kept strictly to washing hands in the chlorinelime, only 45 out of 3556 i.e. 1.27\% children died." (Ref. 1, p. 49) Semmelweis also recognized that not only material from corpses, but substances from infected wounds or disintegrating cancerous tissues that is "rotting material" may cause puerperal fever in the same way (Ref. 1, p. 51).

Semmelweis' greatness and spirituality is well reflected by the following sentence: "Due to my conviction I must admit, solely God alone knows how many people have died prematurely because of me, too. I dealt more with corpses than the other obstetricians generally did." (Ref. 1, p. 55)

Semmelweis was not satisfied with the mere observation of cases offered by unexpected chances and clinical events; to confirm his views he also conducted animal experiments jointly with his friend, Lautneer, an assistant professor who worked beside Rokitansky. They experimented on rabbits, and on nine animals they carried out interventions more or less different form each other. In the first animal, after whelping, a brush moistened and contaminated with filthy exudate from endometritis was introduced into the vagina and the uterine cavity. The animal was well for a time, but it died on the $31^{\text {st }}$ day. In the second animal, the treatment was repeated every day. The animal died within ten days. In the third animal, treatment was begun in the tenth hour after delivery and was continued every day and the animal died on the sixth day. In the fourth experiment, the treatment was started an hour after birth and it was repeated several times with a brush imbued with diluted blood of a man who died of marasmus. Following this, the treatment was continued with pleural and peritoneal exudate from a tuberculosis patient. The animal seemingly remained healthy and gave birth in a month. In the fifth experiment, 12 hours after whelping the animal was repeatedly treated with peritoneal exudate and remained healthy and subsequently successfully gave birth. Later it was killed for some other experimental purposes but no change was found in its body. In four further experiments, the animals were treated - for varying periods - with the peritoneal exudate from a man who deceased due to typhus and with cystic pus of a man who died of cholera. The results of experiments performed in a single animal and with different procedures are not comparable and they are difficult to interpret. However, the findings of detailed autopsies, basically confirmed Semmelweis' idea, because the pathological changes found in the dead animals, without exception, were similar to each other and the findings of those deceased of puerperal fever. Semmelweis evaluates the results of the autopsies like this: "The same changes were found in the corpses of rabbits as in the people who died of puerperal fever or who ultimately died of pyaemia." (Ref. 1, p. 65) 
Then, as his position was not extended in Vienna in 1850 - with his newly received mandate in his pocket as a private teacher of the theoretical obstetrics - he returned to his hometown, Pest-Buda, in October.

The way his contemporaries attacked him - on one of his first evenings at home, in a large company of physicians - demonstrates that they did not understand Semmelweis' recognition: "In the St. Rókus Hospital right now, just like every year, a heavy puerperal fever prevails, although there are not any investigating medical students, whose hands were infected with decomposed organic materials." (Ref. 1, p. 65) Semmelweis answers in his book as follows: "... this is not inconsistent, but actually is in line with my opinion on the management of puerperal fever. I managed to find out by my closer investigation that the obstetrics department of St. Rókus Hospital is not an independent department, but it is subordinated to surgery. The obstetrician chief doctor is the surgery chief doctor as well as the doctor of forensic medicine at the same time. In addition, in the absence of a pathologist the autopsy is performed by the chief doctors of the departments themselves." (Ref. 1, p. 66)

From 1851 until the summer of 1857 he became the head of the Department of Obstetrics at St. Rókus Hospital as an honorary chief doctor. During this time, from a total of 933 births only 8 deaths due to puerperal fever were recorded, which is $0.85 \%$ ! In 1855 , he was appointed professor of practical and theoretical obstetrics at the University of Pest. Here are a few lines from a letter written by him to the competent authorities to describe the impossible material conditions of the clinic:

In this application, among others, the following words can be read: “... how unhealthy the premises of the Department of Obstetrics are, it can be seen from the following.

The laws of highest rank on requirements of hospital equipment prescribe four square fathoms for each bed. As the Clinic of Obstetrics has 26 beds, in compliance with the highest order it ought to possess 104 square fathoms, whereas it only has 41, in addition, there is no room, in which the large numbers of students and midwives could be placed. The other three rooms are so small that its capacity is only enough for the half of the students and midwives, the remaining two rooms are also of the size that they can host all the students and midwives pressed against each other, and their air is harmfully stale for the mothers, as it can easily be understood by any unbiased person.

Between the spaces of the windows of two rooms, three chimneys of the chemistry laboratory are situated, by which, if there is fire in certain stoves, the temperature is unbearably elevated.

The Clinic of Obstetrics possesses rooms but only a single one of them can be used as patient room. As the patients lie scattered among the healthy people, puerperal fever although it is not contagious in itself - in certain conditions can be passed on from one person to another - can spread readily.

The position of the Clinic of Obstetrics is as follows: two windows are facing the northern and six of them are facing the western courtyard. The northern blind court is five feet wide, the bare wall of the neighbouring building rose up to the height of the windows of the Clinic of Obstetrics. In this blind courtyard on the ground, on the first and second floor closets are situated.

On the ground floor joining to the closets, the cesspool of the building is located spreading penetrating smell of its rotting contents. The ground floor premises are taken by the elementary and pathological anatomy and just below the windows of Obstetrics, the drainage canal is found, into which all the fluids of the pathological departments are drained. 
The first floor is dominated by the premises of chemistry. In the corner, where the northern and western courtyards are bordering, the morgue of the clinics can be found. The western blind courtyard is surrounded by a wall which is one fathom wide and three meters high and behind it a vacant plot lies. A part of the mortuary lies in this courtyard and downstairs, on the first floor, again the premises of the elementary, pathological anatomy and chemistry are located." (Ref. 1, p. 68-69)

"The situation is nothing better as to the lectures. As there is no lecture hall at the Clinic of Obstetrics, the professor lecturing on obstetrics is a guest where he is just let in: i.e. in the ground floor hall of pharmacology in winter, in that of the surgery in summer. The fact that the hall at seven o'clock - where there is often only candle light in winter, is not very much attended by the students, is not a tragic event in itself, as the instruction of theoretical obstetrics, in the third year of the faculty - as it is well known - is not worth very much, and the present system will soon be replaced by a more rational one... Bold question of mine: Did we have the right to condemn the country physician who did not recognize a uterine rupture and in his naiveté ligated an intestinal segment? Did he have the opportunity at all during his studies, along with doing his best, to acquire the knowledge of the most difficult practical specialty in an appropriate way? Surgical courses today are indispensable in the education of obstetrics...

Finally, there is not even the slightest chance to conduct gynaecological studies. Although this shortcoming can also be experienced at other obstetric clinics as well. To avoid this, it is common to establish small gynaecological departments. Not long ago, throughout six full years, the professor of obstetrics at St. Rókus Hospital - completely free of chargeran a small gynaecology department, in this way offering a chance to introduce one or another diligent and talented student into this important discipline, and so he could do unspeakably much good for thousands of patients. The professor of obstetrics, however, was banned from it against his will. A tragic mistake, like cutting pouch of bowel, does not happen every day but doctors treat plethora every day instead of the ligation of a polypus; they order rheum with aloe daily instead of taking notice of the ulceration. The young doctor is - from the field of gynaecology - sent into the everyday practice practically untrained, which is really a concern as to maintaining the fairer half of humanity, which, in addition, makes up even its larger part." (Ref. 1, p. 73-74)

The quotation shows not only the reality, the sad state of health care in the nineteenth century Pest, but at the same time, it indicates Semmelweis' enlightened, progressive views, and his medical and educational commitment as well as his skill of organization.

Semmelweis' persistent research work, by thorough and consistent observations, deliberate comparison of the different cases, scientific analysis of the clinical statistical data and his additional animal experiments brought their fruit, i.e. the recognition of the cause of the dreaded disease and thus the possibility of a causal cure, or even more, its prevention.

At the same time his achievement has undoubtedly made him pioneer of the clinical pathophysiological research to whom posterity gave and has given the due and worthy respect as a compensation for the attacks he suffered from his contemporaries and bitterness - many times - from misunderstanding. The saviour of mothers and their children is one of our nation's pride and a role model for all of us. Not only in our country but all over the world his life work is recognized, about which books, plays, films appeared and have appeared ever since. Neither the results nor the message of his tragic but successful life lost any of the 
actuality. An ever growing number of scientific articles - as many as about 400 a year - is published in medical journals on hand washing. Most of them are on monitoring the effectiveness of hand washing, which means trying to use the most modern technology. Today it is not uncommon either that professionals or the society automatically reject significant recognition or discovery without examination and justification. To describe this phenomenon, especially in the Anglo-Saxon area - a new term "Semmelweis reflex" has appeared and is spreading. The figure of Ignác Semmelweis was portrayed in Chicago, and his statue is among the statues of the 12 greatest physicians of the world with Louis Pasteur and Wilhelm Conrad Röntgen (Fig. 3).

This article has been prepared according to Rosivall L (2015): Semmelweis Ignác Fülöp, a klinikai kórélettani kutatás úttörője [Ignác Fülöp Semmelweis, pioneer of clinical pathophysiology]. In: Semmelweis Ignác emlékezetére - 150 évvel a halála után [In memory of Ignatius Semmelweis - 150 years after his death], ed Monos E, Budapest, Semmelweis Kiadó, Budapest, pp. 141-155. With permission.

László Rosivall, $M D, P h D, D S c$

Editor-in-Chief

Institute of Pathophysiology, Semmelweis University

Nagyvárad tér 4, H-1089 Budapest, Hungary

Phone/Fax: +36-1-2100-100;

E-mail: rosivall.laszlo@med.semmelweis-univ.hu

\section{REFERENCE}

1. Semmelweis IF (1861): Die Ätiologie, der Begriff und die Prophylaxis des Kindbettfiebers. C. A. Hartleben's Verlag-Expedition, Pest, Wien and Leipzig. Translated by: Rákóczi K (2012): A gyermekágyi láz kóroktana, fogalma és megelőzése [Puerperal fever, aetiology, concepts and prevention]. Akadémiai Kiadó, Budapest

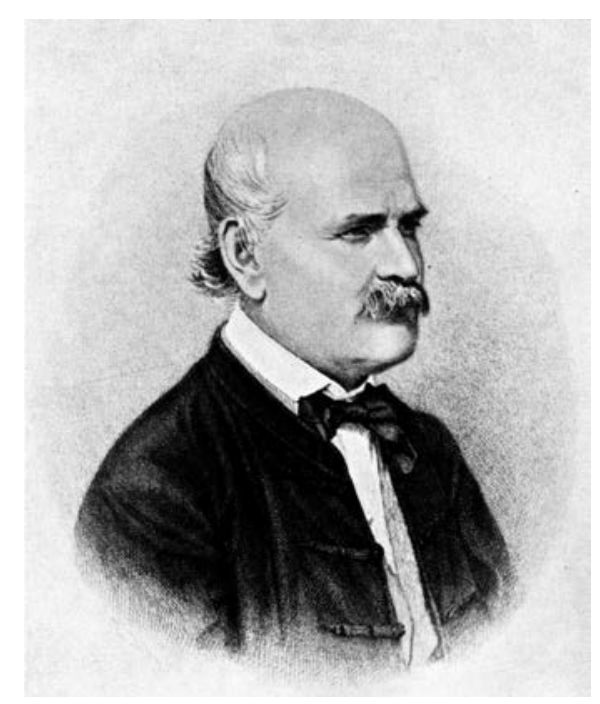

Fig. 1. Portrait of Ignacz Semmelweis, pen drawing by Jenő Doby, Semmelweis University, Presidential Hall, Budapest, Hungary 


\section{Die Aetiologie, der Begriff}

$\rightarrow \operatorname{sid}$

2693

die Prophylaxis

Cis

\section{Kindbettfiebers.}

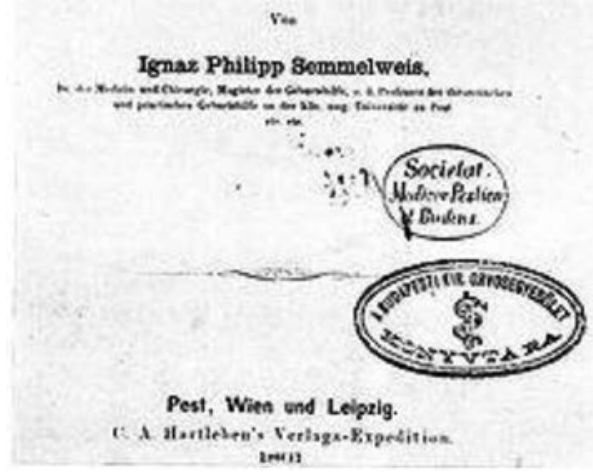

Fig. 2. Semmelweis's main scientific publication:

Die Ätiologie, der Begriff und die Prophylaxis des Kindbettfiebers, 1861 (front page)

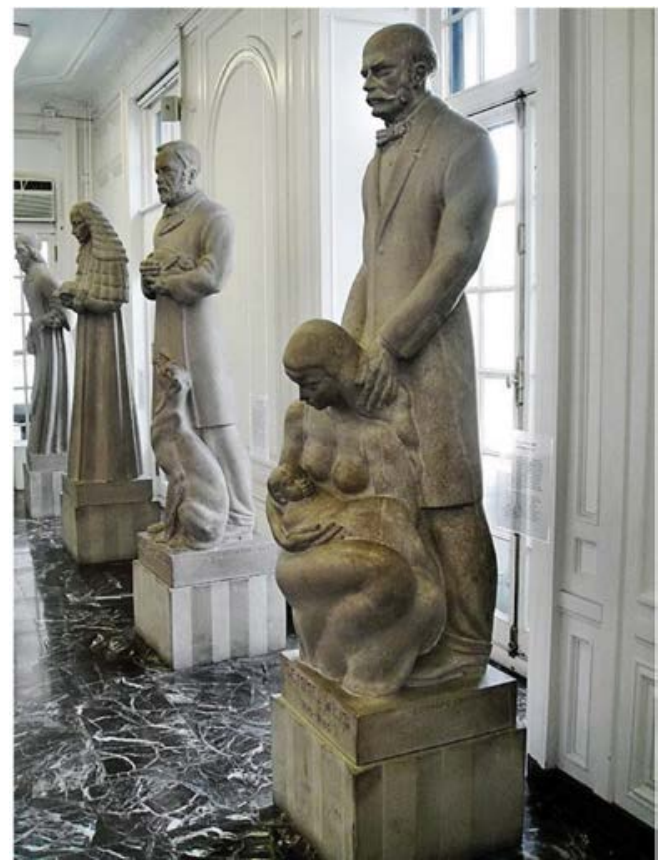

Fig. 3. The life-size statue of Semmelweis in the Hall of Immortals, International Museum of Surgical Science, Chicago, USA 